\title{
Girdin, a regulator of cell motility, is a potential prognostic marker for esophageal squamous cell carcinoma
}

\author{
TAKAHIRO SHIBATA ${ }^{1}$, YOICHI MATSUO ${ }^{1}$, TOMOYA SHAMOTO ${ }^{1}$, TAKAHISA HIROKAWA ${ }^{1}$, \\ KEN TSUBOI ${ }^{1}$, HIROKI TAKAHASHI ${ }^{1}$, HIDEYUKI ISHIGURO ${ }^{1}$, MASAHIRO KIMURA ${ }^{1}$, \\ HIROMITSU TAKEYAMA ${ }^{1}$ and HIROSHI INAGAKI ${ }^{2}$ \\ Departments of ${ }^{1}$ Gastroenterological Surgery, and ${ }^{2}$ Anatomic Pathology and Molecular Diagnostics, \\ Nagoya City University, Nagoya, Aichi 4678601, Japan
}

Received November 28, 2012; Accepted February 18, 2013

DOI: $10.3892 /$ or.2013.2406

\begin{abstract}
Girdin, an actin-binding Akt substrate, regulates actin reconstruction and Akt-dependent cell motility in fibroblasts and in a human breast cancer cell line. We examined whether Girdin is also involved in the motility of esophageal squamous cell carcinoma (ESCC) cells. Immunofluorescent staining and migration assays were performed, using KYSE cell lines, to examine whether Girdin is involved in the motility of ESCC cells. Upon EGF stimulation, Girdin colocalized with filamentous actin (F-actin) in the lamellipodia as determined by immunofluorescent staining. In migration assays, cell motility was significantly reduced in KYSE cell lines transfected with Girdin siRNA compared with the negative control. In addition, we examined the relationship between Girdin expression and clinical data, using specimens resected from ESCC patients. In immunohistochemical (IHC) analyses using specimens resected from ESCC patients, overall survival was significantly longer in cases showing lower Girdin expression compared to cases with higher Girdin expression. Collectively, Girdin appears to be involved in the motility of ESCC cells. The levels of Girdin expression correlated inversely with the survival of ESCC patients. Therefore, in ESCC, Girdin may be a prognostic marker and may serve as a therapeutic target as well.
\end{abstract}

\section{Introduction}

Esophageal cancer is a particularly lethal malignancy. The prognosis for esophageal cancer patients is poor, despite attempts at aggressive multimodality treatment. The 5-year survival rate of esophageal cancer patients is only $40 \%$, having been improved by advances in surgical techniques and adjuvant therapy (1-3).

Correspondence to: Dr Yoichi Matsuo, Department of Gastroenterological Surgery, Nagoya City University, Kawasumi 1, Mizuho-cho, Mizuho-ku, Nagoya, Aichi 4678601, Japan

E-mail: matsuo@med.nagoya-cu.ac.jp

Key words: Girdin, esophageal squamous cell carcinoma, cell motility, prognosis
The absence of a serosal layer allows esophageal malignancies to invade adjacent tissues easily and to spread rapidly (4). Approximately half of the esophageal cancer cases are non-resectable or metastasized (distant stage) when they are diagnosed. Thus, suppressing the motility of cancer cells, which is an important process for invasion and metastasis, is a key to the treatment of esophageal cancer (5). We focused on Girdin, an actin-binding Akt substrate, discovered by Enomoto et al (6). There are numerous reports of the association between Akt and esophageal cancer as well as that between Akt and cell motility. It was also reported that Girdin plays an important role in cell motility of fibroblasts and a breast cancer cell line $(6,7)$.

Migrating cells form protrusive structures such as filopodia and lamellipodia. Lamellipodia are two dimensional, sheet-like structures containing a cross-linked mesh of actin filaments (8). Girdin forms dimers through the $\mathrm{NH}_{2}$ terminal domain. Moreover, Girdin, in which the serine at position 1416 is phosphorylated by Akt binds actin filaments via the $\mathrm{COOH}$-terminal domain (6). Based on these results and immunofluorescent staining of Vero fibroblasts and a breast cancer cell line, it is considered that Girdin cross-links actin filaments and is involved in the formation of lamellipodia in fibroblasts and breast cancer (6,7).

Esophageal cancer is divided mainly into two histological subtypes, ESCC and adenocarcinoma. Although adenocarcinoma is the most prevalent subtype $(>50 \%)$ of esophageal cancer in the USA (9), $>90 \%$ of esophageal cancer cases are ESCC in Japan $(10,11)$. Thus, in the present study we investigated whether Girdin is also involved in the motility of ESCC cells. We used a human ESCC cell line, KYSE series. Furthermore, we examined whether there was a correlation between Girdin expression and the prognosis of ESCC patients, using specimens resected from ESCC patients. To the best of our knowledge, this is the first report to describe the inverse correlation of Girdin expression with the survival of ESCC patients.

\section{Materials and methods}

Antibodies. Rabbit anti-Girdin polyclonal antibodies and rabbit anti-p-Girdin (phospho-S1417) antibody were purchased 
from Abcam (Cambridge, MA, USA). Other antibodies used in this study included polyclonal goat anti-rabbit immunoglobulins/HRP (Dako, Glostrup, Denmark) and Alexa Fluor ${ }^{\circledR}$ 488 goat anti-rabbit IgG (green) (Life Technologies Corp., Carlsbad, CA, USA).

Cells. KYSE (human ESCC) cell lines were obtained from the Japanese Collection of Research Bioresources (Tokyo, Japan). Het1A, a normal human esophageal mucosal cell line, was purchased from ATCC (Manassas, VA, USA). They were cultured in RPMI-1640 (Sigma-Aldrich, St. Louis, MO, USA) supplemented with $10 \%$ fetal bovine serum (FBS) $\left(\right.$ Gibco $^{\circledR}$, Life Technologies Corp.), $100 \mathrm{U} / \mathrm{ml}$ penicillin G, $100 \mu \mathrm{g} / \mathrm{ml}$ streptomycin and $250 \mathrm{ng} / \mathrm{ml}$ amphotericin B.

Real-time polymerase chain reaction (RT-PCR). Total RNA was extracted from KYSE cells or specimens resected from ESCC patients, using RNeasy ${ }^{\circledR}$ Plus Mini kit (Qiagen, Hilden, Germany) according to the manufacturer's instructions. The reverse transcription reaction was subsequently carried out using SuperScript ${ }^{\mathrm{TM}}$ III First-Strand Synthesis SuperMix for qRT-PCR (Life Technologies) according to the manufacturer's instructions. PCR amplification of the cDNA template corresponding to 20 ng total RNA was performed using TaqMan Universal PCR Master Mix (Applied Biosystems, Foster City, CA, USA) in a Chromo4 ${ }^{\mathrm{TM}}$ System (Bio-Rad Laboratories, Hercules, CA, USA). Girdin primer was purchased from Applied Biosystems (Foster City, CA, USA). PCR conditions were $50^{\circ} \mathrm{C}$ for $2 \mathrm{~min}$ and $95^{\circ} \mathrm{C}$ for $10 \mathrm{~min}$ followed by 40 cycles of $95^{\circ} \mathrm{C}$ for $15 \mathrm{sec}$, and $60^{\circ} \mathrm{C}$ for $1 \mathrm{~min}$. The expression levels of Girdin were normalized against glyceraldehyde 3-phosphate dehydrogenase (GAPDH) (Human GAPDH Endogenous Control, Applied Biosystems $\left.{ }^{\circledR}\right)$.

Immunofluorescent staining. KYSE270 cells were seeded on poly-L-lysine (PLL)-coated cover glass in base dishes and incubated for $21 \mathrm{~h}$. Then, cells were serum-starved for $3 \mathrm{~h}$ and incubated for $1 \mathrm{~h}$ in a medium with or without EGF. The cells were fixed with $3.7 \%$ formaldehyde. Subsequently, immunofluorescent staining was performed using anti-Girdin antibody, Alexa Fluor ${ }^{\circledR} 488$ goat anti-rabbit IgG (green) (Life Technologies), Alexa Fluor ${ }^{\circledR} 555$ Phalloidin (red) (Life Technologies) and 4',6-diamidino-2-phenylindole (DAPI) (blue) (Dojindo Laboratories, Kumamoto, Japan). Fluorescence was observed using a confocal laser-scanning microscope (Carl Zeiss, Oberkochen, Germany).

Small interfering RNA (siRNA)-mediated Girdin knockdown. siRNA-mediated knockdown of Girdin was performed. Referring to RNA interference which Enomoto et al (6) performed, the sequences coding the siRNA targeted on Girdin were (only the sense sequence is shown): 5'-AACCAGGTC ATGCTCCAAATT-3' (nucleotides 145-165, Girdin siRNA1) and 5'-AAGAAGGCTTAGGCAGGAATT-3' (nucleotides 780-800, Girdin siRNA2). The 21 nucleotide synthetic duplexes mentioned above were prepared by Qiagen. Cells were transfected with Girdin siRNA or negative control siRNA (AllStars Negative siRNA Alexa Fluor 488, Qiagen), using Lipofectamine ${ }^{\mathrm{TM}} 2000$ (Life Technologies) according to the manufacturer's instructions.
Western blot analysis. We extracted proteins from KYSE cells that had been lysed in IP kinase buffer with $1 \%$ Halt $^{\mathrm{TM}}$ Protease Inhibitor Single-Use Cocktail (Thermo Fisher Scientific, Waltham, MA, USA) and $1 \%$ Halt $^{\mathrm{TM}}$ Phosphatase Inhibitor Cocktail (Thermo Fisher Scientific), using a sonicator, Bioruptor $^{\circledR}$ (Cosmo Bio, Tokyo, Japan).

In western blot analysis, the sample proteins were separated on $8 \%$ SDS-PAGE. Proteins were transferred to nitrocellulose membranes, blocked in 3\% non-fat skin milk in phosphatebuffered saline (PBS), incubated with primary antibodies, rabbit polyclonal anti-Girdin (Abcam) and detected with horseradish peroxidase (HRP)-conjugated secondary antibodies (polyclonal goat anti-rabbit immunoglobulins, Dako). For visualization, SuperSignal ${ }^{\circledR}$ West Pico Chemiluminescent Substrate (Thermo Fisher Scientific) with $10 \%$ SuperSignal ${ }^{\circledR}$ West Femto Trial kit (Thermo Fisher Scientific) was used. Imaging of western blots was performed using ImageQuant LAS 4000 mini (Fujifilm, Tokyo, Japan) according to the manufacturer's instruction.

Migration assay. Migration assays were performed using growth factor reduced Matrigel ${ }^{\mathrm{TM}}$ invasion chambers (BD Biosciences, Bedford, MA, USA) according to the manufacturer's instructions. KYSE cells $\left(2 \times 10^{5}\right)$ transfected with control siRNA or Girdin siRNA were seeded in Matrigelcoated invasion chambers. The chambers were then placed into 24-well plates, into which basal medium only or basal medium containing $1.0 \mathrm{ng} / \mathrm{ml}$ epidermal growth factor (EGF) (BD Biosciences) was added. Following incubation of KYSE cells for $12 \mathrm{~h}$, the upper surface of the Transwell chambers was wiped with a cotton swab. The migrating cells were fixed, stained with Diff-Quick (Sysmex, Kobe, Japan), and counted in 5 random microscopic fields (x200). The experiment was performed three times with each sample in triplicate. The results were normalized and expressed as an invasion index, in which the lowest number of migrating cells in this experiment was designated as 1 .

Patients and tumor samples. Patients who had been diagnosed with ESCC and had undergone esophagectomy at Nagoya City University were selected for this study. All patients were followed up for at least 5 years from the time of operation, unless they died or the data were censored. This study was approved by the Institutional Review Board, and written consent was obtained from each patient.

Immunohistochemistry. Paraffin-embedded specimens that had been resected from ESCC patients were analyzed for Girdin expression by immunohistochemistry (IHC). For fluorescence staining of the ESCC tissues, the sections were stained with anti-Girdin polyclonal antibody, followed by the secondary antibody, and were observed with a light microscope. All processes of IHC were performed using BOND-MAX (Leica, Wetzlar, Germany).

Results of each IHC staining were evaluated as follows; the stained cells were counted in five random microscopic fields (x200); the intensity of tissue staining was graded semiquantitatively on a four-point scale $(-,+,++$ and +++$)$, and the proportion of the stained cells was assessed on a four-tier scale (1, $0-15 \% ; 2,15-50 \% ; 3,50-85 \%$; and 4, 85-100\% cells stained). Staining was scored by 3 independent observers blinded to the 


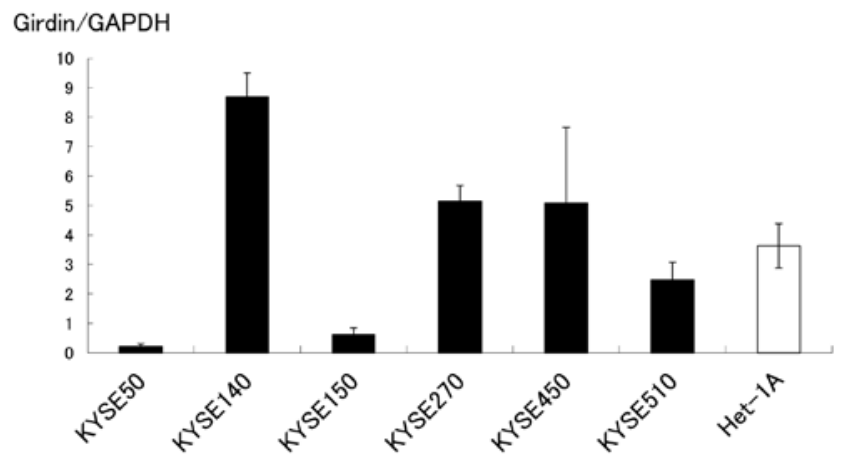

Figure 1. Expression of Girdin mRNA in cell lines. KYSE cell lines (esophageal squamous cell carcinoma cell lines) and Het1A (a normal human esophageal squamous cell line) were analyzed by real-time PCR. Expression of Girdin mRNA was detected in all cell lines that were examined. Columns, means; bars, SD. Experiments were performed in triplicate and were repeated three times.

disease stage and the patient outcome with $>95 \%$ agreement. The cases were classified into a strong staining group and a weak staining group by the intensity and proportion of immunostained cancer cells. The cases where the immunostaining intensity was more than ++ and the proportion was $>3$ were defined as a strong staining group.

Statistical analysis. The biostatistical analyses were performed with StatView software (Abacus Concepts, Berkeley, CA, USA). Kaplan-Meier estimates of overall survival time were compared using the log-rank test. $\mathrm{P}<0.05$ was considered to indicate a statistically significant difference. We used unpaired Student's t-test to compare mean age, Fisher's exact test to compare gender ratio, and Yates's chi-squared test to compare other patient characteristics.

\section{Results}

Girdin expression is detected in HetlA and KYSE cell lines. Using RT-PCR, expression of Girdin mRNA in KYSE cell lines and Het1A was detected in all cell lines examined (Fig. 1).

Girdin is involved in the formation of lamellipodia in KYSE cell lines stimulated by EGF. The subcellular localization of Girdin was investigated using immunofluorescent staining. Girdin and F-actin were localized diffusely throughout the cytoplasm in quiescent cells (Fig. 2, upper panel). By contrast, EGF-stimulated KYSE270 cells extended lamellipodia, where Girdin was preferentially colocalized with F-actin (Fig. 2, bottom panel). Girdin may play an important role in cell motility by reconstruction of the actin cytoskeleton at the leading edge of ESCC cells.

Cell motility is reduced in KYSE cells in which Girdin is depleted by RNA interference. KYSE270, KYSE450 and KYSE510 cell lines were transfected with either control siRNA or Girdin siRNA. The knockdown of Girdin was confirmed by RT-PCR and western blot analyses. Both the Girdin mRNA level (Fig. 3A) and the Girdin protein level (Fig. 3B) were significantly lower in the cell lines transfected with Girdin siRNA than in the cell lines transfected with control siRNA.

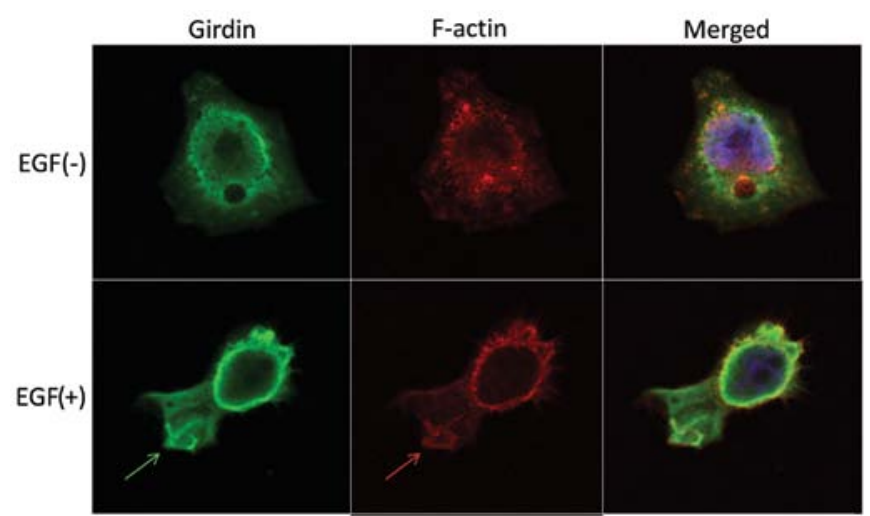

Figure 2. Girdin is involved in the formation of lamellipodia in epidermal growth factor (EGF)-stimulated KYSE cell lines. KYSE270 cells were incubated for $1 \mathrm{~h}$ with or without EGF, fixed, and assessed by immunofluorescent staining with anti-Girdin antibody, Alexa Fluor $^{\circledR} 488$ goat anti-rabbit IgG (green), Alexa Fluor ${ }^{\circledR} 555$ phalloidin (red) and 4',6-diamidino-2-phenylindole (DAPI) (blue). In quiescent KYSE270 cells, Girdin and filamentous actin (F-actin) were seen diffusely throughout the cytoplasm (upper panel). EGFstimulated KYSE270 cells extended lamellipodia (bottom panel). A green arrow and a red arrow indicate the accumulation of Girdin and that of F-actin at the tip of the lamellipodia, respectively.

A

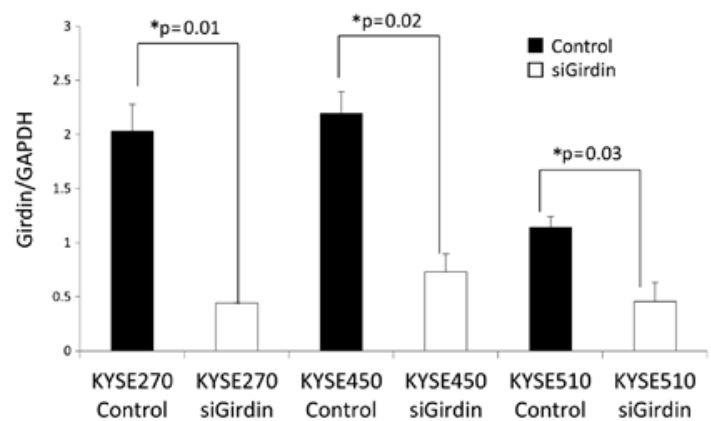

B

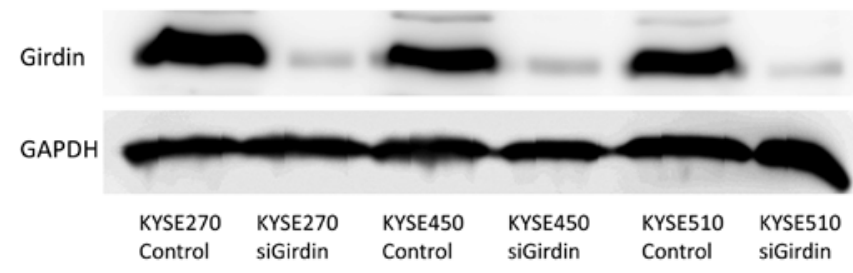

Figure 3. Transfection of KYSE cell lines with control siRNA or Girdin siRNA. (A) The knockdown of Girdin was confirmed by RT-PCR. Columns, means; bars, SD. *Statistical significance (paired Student's t-test, two-tailed $\mathrm{P}<0.05)$. Experiments were performed in triplicate and were repeated three times. (B) The knockdown of Girdin was also confirmed by western blot analysis using anti-Girdin antibody and anti-GAPDH antibody. The Girdin protein levels were significantly lower in the cell lines transfected with Girdin siRNA than in the cell lines transfected with control siRNA.

Boyden chamber assays were used to assess cell migration in vitro. In KYSE cell lines transfected with control siRNA, the migration index was higher in cells incubated in medium with EGF compared to cells incubated in medium without EGF. The migration index was also significantly higher in cells transfected with control siRNA than in cells transfected with Girdin siRNA (Fig. 4). 

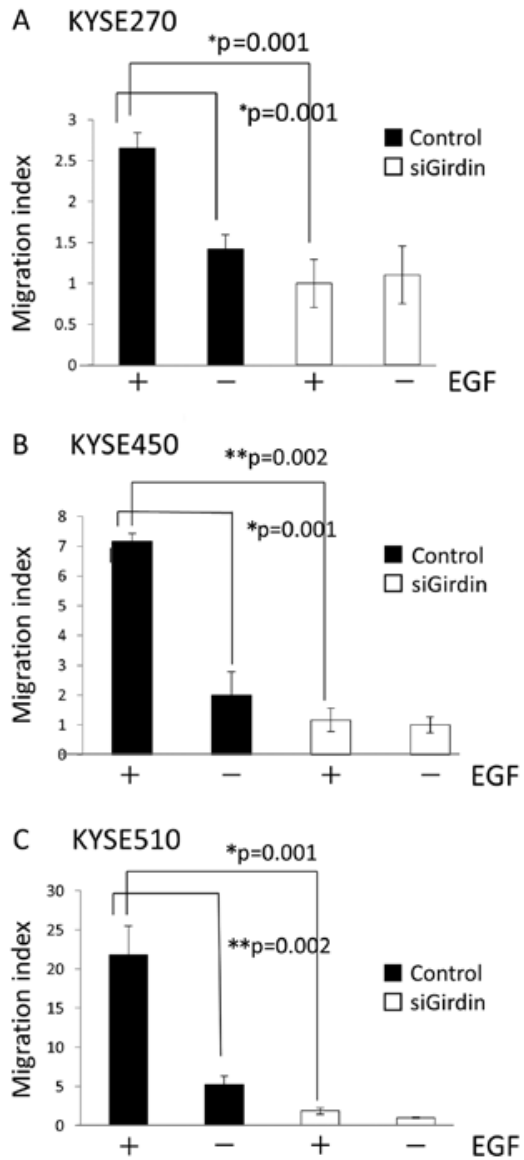

Figure 4. In vitro cell migration assay in Boyden chambers. Forty-eight hours after transfection of KYSE270, KYSE450 and KYSE510 cells with either control siRNA or Girdin siRNA, cells were seeded in the upper chamber and incubated for $12 \mathrm{~h}$. Results are expressed as the migration index, in which the lowest ratio was designated as 1 . In KYSE cell lines transfected with control siRNA, the migration index was higher in the cells incubated in medium with EGF compared with the cells incubated in medium without EGF. The migration index was also significantly higher in cells transfected with control siRNA than in cells transfected with Girdin siRNA. Columns, means; bars, SD. ${ }^{*} \mathrm{p}=0.001 ;{ }^{* *} \mathrm{p}=0.002$ (paired Student's t-test, two-tailed). Experiments were performed in triplicate and were repeated three times.

Girdin expression is significantly higher in tumor tissue than in paired normal esophageal squamous mucosa in ESCC. We compared Girdin mRNA levels in tumor tissues with those of paired adjacent normal mucosa, using specimens resected from 62 ESCC patients who had undergone esophagectomy at the Nagoya City University from 1996 to 2001. Total RNA was extracted from esophageal cancer tissues and from paired normal esophageal mucosa using RNeasy ${ }^{\circledR}$ Plus Mini Kit (Qiagen) and subsequently subjected to RT-PCR. Data showed that Girdin mRNA from tumor tissue was significantly higher than that from paired adjacent normal mucosa in ESCC (Fig. 5).

High Girdin expression correlates with poor prognosis in ESCC. We next investigated whether expression levels of Girdin were associated with patient 5-year survival rate following surgery. We performed IHC using specimens resected from 73 ESCC patients who had undergone esophagectomy at the Nagoya City Hospital from 1996 to 2006. Although neoadjuvant chemotherapy for stage II or III (Japanese classification of esophageal cancer) cases is standard in Japan, patients who had

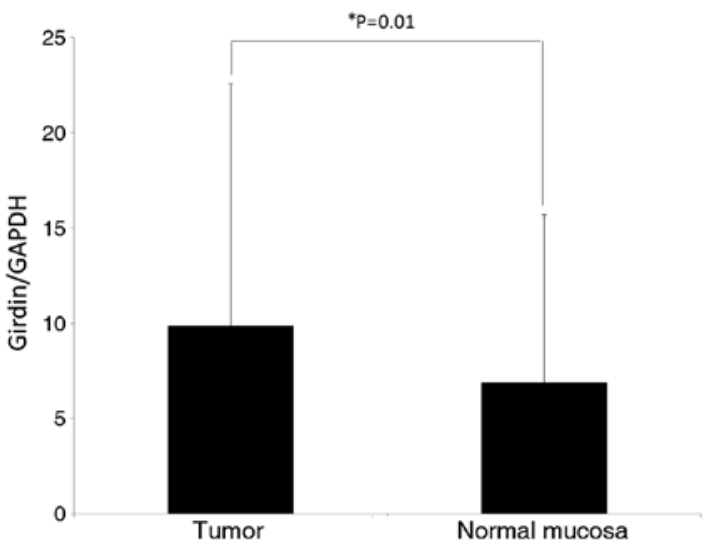

Figure 5. RT-PCR analysis of mRNA extracted from tumor tissue and from paired normal esophageal mucosa. mRNA extracted from tumor tissue was compared with that from paired normal esophageal mucosa of specimens resected from esophageal squamous cell carcinoma (ESCC) patients. Girdin mRNA was significantly higher in tumor tissue than in normal mucosa. Columns, means; bars, SD. "Statistical significance (two-tailed $\mathrm{P}<0.05$ by Wilcoxon signed-rank test). Experiments were performed in triplicate and were repeated three times.

undergone chemotherapy and/or irradiation prior to surgery were excluded from this study, considering the influence of these therapies on Girdin expression of the tumor tissue.

The invasion of primary tumors was significantly deeper in the strongly staining group than in the weakly staining group (T1 vs. T2-T4, $\mathrm{P}=0.024$ ). There was no significant difference with regard to the other patient characteristics (Table I). Kaplan-Meier curves show that patients whose tumor tissue was stained weakly (Fig. 6A, right panel) had prolonged survival compared to patients whose tumor tissue was stained strongly (Fig. 6A, left panel) (two-tailed $\mathrm{P}=0.042$, log-rank test) (Fig. 6B).

\section{Discussion}

Cell motility is considered to be an important process for invasion and metastasis of invasive cancer cells. In animals, almost all cells move by crawling (12). Cell crawling is composed of three distinctive phases, protrusion, attachment and traction (13). In protrusion, different cell types generate a variety of protrusive structures, such as filopodia, lamellipodia and pseudopodia (14). Epithelial cells, some types of fibroblasts and some neurons form lamellipodia, which are two dimensional, sheet-like structures containing a cross-linked mesh of actin filaments (8). Activation of Rac, a member of the Rho protein family, by extracellular signals leads to actin nucleation by the ARP complex and actin cross-linking by filamin (15-17). Reconstruction of actin filaments forms actin networks in lamellipodia.

Akt, serine/threonine kinase, has multiple effects on cells, including survival, proliferation and growth (18). Moreover, it is involved in cell migration (19). However, the underlying mechanism is not well understood. Enomoto et al (6) identified an Akt substrate using a yeast two-hybrid screen of a human fetal brain cDNA library, and designated it Girdin. Akt phosphorylates serine at position 1416 in Girdin. Based on studies of Vero fibroblasts and the MDA-MB231 breast cancer cell 
Table I. Mean age, gender ratio and the histological characteristics of the two patient groups whose tumors stained strongly and weakly in immunohistochemistry for Girdin.

\begin{tabular}{|c|c|c|c|}
\hline \multirow[b]{2}{*}{ Characteristics } & \multicolumn{2}{|c|}{ Girdin expression } & \multirow[b]{2}{*}{ P-value } \\
\hline & $\begin{array}{l}\text { Strongly } \\
\text { staining } \\
(\mathrm{n}=50)\end{array}$ & $\begin{array}{l}\text { Weakly } \\
\text { staining } \\
(n=23)\end{array}$ & \\
\hline Mean age $( \pm \mathrm{SD})$ & $63.6 \pm 8.3$ & $62.2 \pm 8.6$ & NS \\
\hline \multicolumn{4}{|l|}{ Gender } \\
\hline Male & 41 & 18 & NS \\
\hline Female & 9 & 5 & \\
\hline \multicolumn{4}{|l|}{ Primary tumor } \\
\hline $\mathrm{T} 1$ & 11 & 11 & 0.024 \\
\hline $\mathrm{T} 2$ & 9 & 2 & (T1 vs. T2-4) \\
\hline T3 & 21 & 6 & \\
\hline $\mathrm{T} 4$ & 9 & 4 & \\
\hline \multicolumn{4}{|l|}{$\begin{array}{l}\text { Lymph node } \\
\text { metastasis }\end{array}$} \\
\hline Positive & 33 & 8 & NS \\
\hline Negative & 17 & 15 & \\
\hline \multicolumn{4}{|l|}{ Remote metastasis } \\
\hline Positive & 5 & 1 & NS \\
\hline Negative & 45 & 22 & \\
\hline \multicolumn{4}{|l|}{ TNM stage } \\
\hline 0 & 0 & 1 & NS \\
\hline 1 & 12 & 6 & (stage $0-1$ vs. $2-4$ ) \\
\hline 2 & 9 & 3 & (stage $0-2$ vs. $3-4$ ) \\
\hline 3 & 24 & 12 & \\
\hline 4 & 5 & 1 & \\
\hline \multicolumn{4}{|c|}{ Lymphatic invasion } \\
\hline Positive & $38^{a}$ & $12^{\mathrm{b}}$ & NS \\
\hline Negative & $10^{\mathrm{a}}$ & $8^{\mathrm{b}}$ & \\
\hline \multicolumn{4}{|l|}{ Venous invasion } \\
\hline Positive & $31^{\mathrm{a}}$ & $8^{a}$ & NS \\
\hline Negative & $17^{\mathrm{a}}$ & $13^{\mathrm{a}}$ & \\
\hline
\end{tabular}

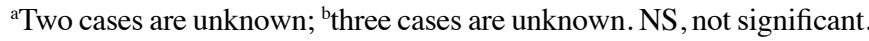

line, it is likely that phosphorylated Girdin colocalizes with actin filaments in the lamellipodia and plays a crucial role in the motility of those cells $(6,7)$. In the present study, we examined whether Girdin was also involved in the motility of ESCC cells.

Girdin is reportedly highly expressed in a variety of human malignant tissues including breast, colon, lung, thyroid and uterine cervical carcinomas (7). We analyzed Girdin mRNA expression in KYSE cell lines and Het1A by RT-PCR. Expression of mRNA was confirmed in all cell lines that we examined. For the following experiments we selected KYSE270, KYSE450 and KYSE510 in which expression of Girdin mRNA was high.
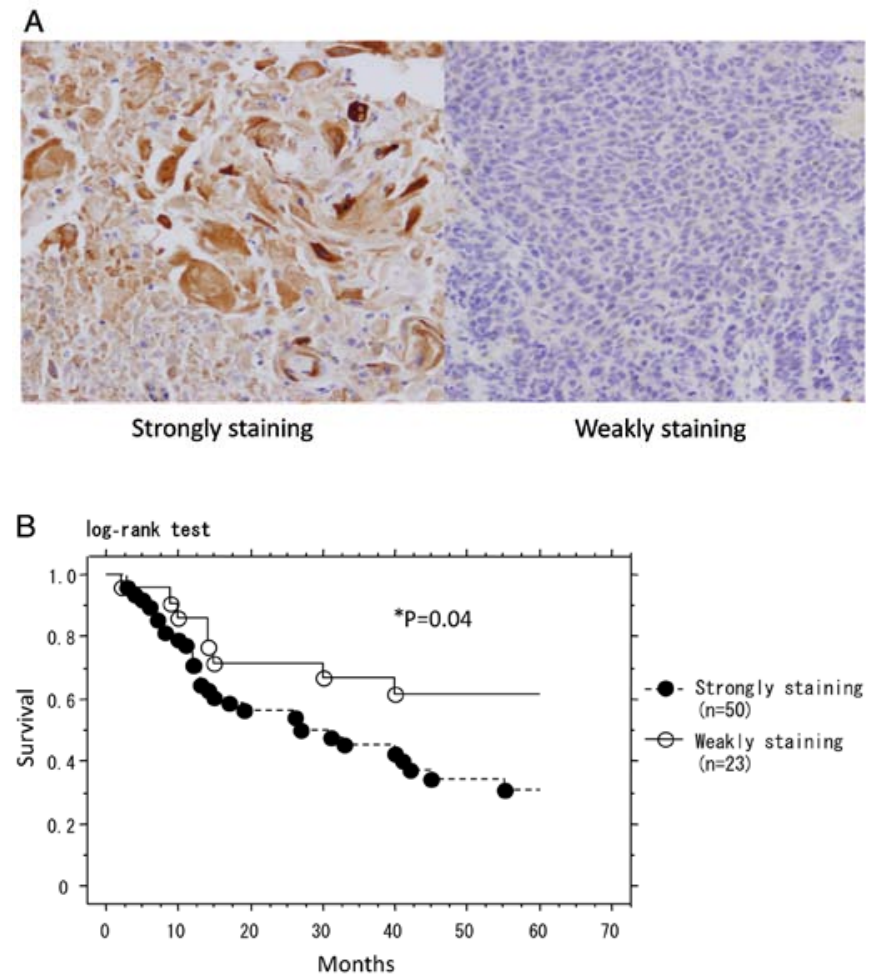

Figure 6. Immunohistochemistry (IHC) of specimens resected from esophageal squamous cell carcinoma (ESCC) patients. (A) Representative findings of tumors stained strongly (left) or weakly (right). Paraffin-embedded human ESCC samples were analyzed for Girdin expression by IHC using anti-Girdin antibody. (B) Kaplan-Meier survival curves for ESCC patients. Log-rank analysis of the Kaplan-Meier curves showed that patients whose tumor tissue was stained weakly had prolonged survival compared to patients whose tumor epithelium was stained strongly.

To visualize the involvement of Girdin in the formation of lamellipodia, we performed immunofluorescent staining. Colocalization of Girdin and F-actin was observed in the lamellipodia in response to EGF stimulation. In migration experiments, cell motility was reduced in KYSE cell lines compared to controls when Girdin was depleted by Girdin siRNA.

Collectively, the results of this study suggest that Girdin plays an important role in the motility of ESCC cells. We investigated the relationship between Girdin expression and clinical data in ESCC cases. In RT-PCR analyses of specimens resected from ESCC patients, Girdin mRNA extracted from tumor tissue was significantly higher than that from paired normal esophageal epithelium. Girdin may be expressed in normal cells of several tissues, as it is involved not only in the motility of cancer cells but also in functions such as angiogenesis and neurogenesis. This result suggests that increased Girdin expression in esophageal squamous cells enhances their ability to invade surrounding tissues when they become cancerous. In IHC, the invasion of primary tumors was significantly deeper in the strong staining group than in the weak staining group, which may reflect Girdin's function in cell motility. Garcia-Marcos et al (20) reported that there was a significant inverse correlation between Girdin expression and disease-free survival of stage II colorectal cancer patients. In the present study, it was shown that higher expression levels of Girdin were also associated with shorter postoperative survival in ESCC. 
In esophageal cancer, prognostic markers such as E-cadherin, MDM2 and HGF have been reported (21-23). We previously showed that expression of DNA fragmentation factor 45, excision repair cross complementing 3 , and PABPC1 may be prognostic markers for ESCC (24-26). Girdin may now be added to this list. Our data indicate that Girdin may be a suitable candidate for a molecular prognosis marker for ESCC. Girdin may also become a therapeutic target in ESCC.

We analyzed the relationship between Girdin and ESCC for the first time. Girdin appeared to be involved in the motility of ESCC cells, and the level of its expression correlated inversely with the survival rate of ESCC patients. In ESCC, Girdin may be a prognostic marker and it may serve as a therapeutic target as well.

\section{Acknowledgements}

The authors thank Hisashi Takino (Department of Anatomic Pathology and Molecular Diagnostics, Nagoya City University) for immunostaining for resected specimens of ESCC.

\section{References}

1. Kuwano H, Nakajima M, Miyazaki T and Kato H: Distinctive clinicopathological characteristics in esophageal squamous cell carcinoma. Ann Thorac Cardiovasc Surg 9: 6-13, 2003.

2. Ando N, Ozawa S, Kitagawa Y, Shinozawa Y and Kitajima M: Improvement in the results of surgical treatment of advanced squamous esophageal carcinoma during 15 consecutive years. Ann Surg 232: 225-232, 2000.

3. Hofstetter W, Swisher SG, Correa AM, et al: Treatment outcomes of resected esophageal cancer. Ann Surg 236: 376-384, 2002.

4. Boyce GA and Boyce BH: Esophagus. In: Text of Gastroenterology. Yamada TY, Alpers DH and Laine L (eds). Lippincott Williams and Wilkins, Philadelphia, PA, pp1180-1195, 2003.

5. Yamazaki D, Kurisu S and Takenawa T: Regulation of cancer cell motility through actin reorganization. Cancer Sci 96: 379-386, 2005.

6. Enomoto A, Murakami H, Asai N, et al: Akt/PKB regulates actin organization and cell motility via Girdin/APE. Dev Cell 9 389-402, 2005.

7. Jiang P, Enomoto A, Jijiwa M, et al: An actin-binding protein Girdin regulates the motility of breast cancer cells. Cancer Res 68: 1310-1318, 2008.

8. Rivas RJ and Hatten ME: Motility and cytoskeletal organization of migrating cerebellar granule neurons. J Neurosci 15: 981-989, 1995.

9. Trivers KF, Sabatino SA and Stewart SL: Trends in esophageal cancer incidence by histology, United States, 1998-2003. Int J Cancer 123: 1422-1428, 2008.
10. Ide H, Udagawa H, Ozawa $\mathrm{S}$, et al: The Japanese Society for Esophageal Diseases: Comprehensive registry of esophageal cancer in Japan $(1998,1999)$. The Japanese Society for Esophageal Diseases, Tokyo, 2002.

11. Ozawa S, Tachimori Y, Baba H, et al: Comprehensive registry of esophageal cancer in Japan, 2002. Esophagus 7: 7-22, 2010.

12. Harris AK: A dozen questions about how tissue cells crawl. Biochem Soc Symp 65: 315-341, 1999.

13. Roy S, Miao F and Qi HJ: Cell crawling assisted by contractile stress induced retraction. J Biomech Eng 132: 061005, 2010.

14. Olson MF and Sahai E: The actin cytoskeleton in cancer cell motility. Clin Exp Metastasis 26: 273-287, 2009.

15. Machesky LM and Hall A: Role of actin polymerization and adhesion to extracellular matrix in Rac- and Rho-induced cytoskeletal reorganization. J Cell Biol 138: 913-926, 1997.

16. Welch MD: The world according to Arp: regulation of actin nucleation by the Arp2/3 complex. Trends Cell Biol 9: 423-427, 1999.

17. Ohta Y, Suzuki N, Nakamura S, Hartwig JH and Stossel TP: The small GTPase RalA targets filamin to induce filopodia. Proc Natl Acad Sci USA 96: 2122-2128, 1999.

18. Altomare DA and Khaled AR: Homeostasis and the importance for a balance between AKT/mTOR activity and intracellular signaling. Curr Med Chem 19: 3748-3762, 2012.

19. Qian Y, Corum L, Meng Q, et al: PI3K induced actin filament remodeling through Akt and p70S6K1: implication of essential role in cell migration. Am J Physiol Cell Physiol 286: C153-C163, 2004.

20. Garcia-Marcos M, Jung BH, Ear J, Cabrera B, Carethers JM and Ghosh P: Expression of GIV/Girdin, a metastasis-related protein, predicts patient survival in colon cancer. FASEB J 25: 590-599, 2011.

21. Lin YC, Wu MY, Li DR, Wu XY and Zheng RM: Prognostic and clinicopathological features of E-cadherin, alpha-catenin, beta-catenin, gamma-catenin and cyclin D1 expression in human esophageal squamous cell carcinoma. World J Gastroenterol 10: 3235-3239, 2004.

22. Shimada Y, Imamura M, Shibagaki I, et al: Genetic alterations in patients with esophageal cancer with short- and long-term survival rates after curative esophagectomy. Ann Surg 226: 162-168, 1997.

23. Ren Y, Cao B, Law S, et al: Hepatocyte growth factor promotes cancer cell migration and angiogenic factors expression: a prognostic marker of human esophageal squamous cell carcinomas. Clin Cancer Res 11: 6190-6197, 2005.

24. Konishi S, Ishiguro H, Shibata Y, et al: Decreased expression of DFF45/ICAD is correlated with a poor prognosis in patients with esophageal carcinoma. Cancer 95: 2473-2478, 2002.

25. Terashita $\mathrm{Y}$, Ishiguro $\mathrm{H}$, Haruki $\mathrm{N}$, et al: Excision repair cross complementing 3 expression is involved in patient prognosis and tumor progression in esophageal cancer. Oncol Rep 12: 827-831, 2004.

26. Takashima N, Ishiguro H, Kuwabara Y, et al: Expression and prognostic roles of PABPC1 in esophageal cancer: correlation with tumor progression and postoperative survival. Oncol Rep 15: 667-671,2006. 